\title{
RNA Inference: A New Technology for Genetic Improvement of Major Fruit Species
}

\author{
Amardeep Kour* and Navjot Gupta \\ PAU, Regional Research Station, Bathinda, India \\ *Corresponding author
}

\begin{tabular}{|l|}
\hline Ke y w o r d s \\
$\begin{array}{l}\text { Fruit crop quality } \\
\text { improvement, } \\
\text { Functional } \\
\text { genomics, Insect- } \\
\text { pest resistance, } \\
\text { RNAi }\end{array}$ \\
\hline Article Info \\
\hline $\begin{array}{l}\text { Accepted: } \\
\text { 12 February } 2019 \\
\text { Available Online: } \\
\text { 10 March } 2019\end{array}$ \\
\hline
\end{tabular}

\section{Keywords}

Fruit crop quality improvement,

Functional genomics, Insectpest resistance

Article Info

Accepted:

10 March 2019

\begin{abstract}
A B S T R A C T
The improvement of woody fruit species by conventional plant breeding techniques has several limitations because of high degree of heterozygosity, lengthy juvenile period and auto-incompatibility. The development of new biotechnological tools (NBTs), such as RNA interference (RNAi), trans-grafting, cisgenesis/intragenesis, and genome editing tools, like zinc-finger and CRISPR/Cas9, has introduced the possibility of more precise and faster genetic modifications of plants. For the introduction or modification of specific traits in woody fruit species while maintaining unchanged general characteristics of a selected cultivar, this aspect is of particular importance. Over the decades biotechnological tools have undergone rapid development and there is a continuous addition of new and valuable techniques for plant breeders. This makes it possible to create desirable woody fruit varieties in a fast and more efficient way to meet the demand for sustainable agricultural productivity. In mid ninety's RNA interference (RNAi) added a new dimension in the regulation of gene expression by different types of RNA. Down regulation of the expression of specific genes through RNAi, has been widely used for genetic research (Agarwal et al., 2003; Mansoor et al., 2006; Angaji et al., 2010). The technique has revolutionized the studies on basic biological phenomenon and unrevealed many hidden facts in every domain of biological science including Agriculture. This review article summarizes the applications of RNA interference in fruit plants for functional genomics, quality improvement and disease and insect -pest resistance.
\end{abstract}

\section{Introduction}

Improvement of woody fruit species using conventional breeding methods is a long term and slow process because of their long gestation period, high heterozygosity, extended juvenile periods, and autoincompatibility. Advances in modern biology, especially biotechnology, offer many advantages over traditional techniques of plant breeding. Among those various recent biotechnological tools, RNA Interference has been playing important role in fruit crop improvement. RNAi is a natural phenomenon that was considered an oddity when it was first observed in petunias. It exists in many organisms as a means of protecting against viruses and transposons, molecular invaders that would otherwise plague a host genome and wreak havoc. With the advent of refinement in biotechnological tools this concept has been turned into a new technique 
that is able to suppress the expression of specific endogenous genes through the use of double-stranded RNA (dsRNA). The technique was first demonstrated in Caenorhabditis elegans (Fire et al., 1998) and subsequently in human and other mammalian cells. The new technology, called $R N A$ interference (RNAi), is also frequently called gene knockdown. The technique has revolutionized the studies on basic biological phenomenon and unrevealed many hidden facts in every domain of every biological science including Agriculture. Horticultural science has also been covered in this domain with wide applications in, functional genomics, down regulation of undesirable traits and development of new generation insect or disease resistant crops. By expressing inducers of post-transcriptional gene silencing homologous to iaaM and ipt in plant cells, the corresponding oncogene mRNA transcripts are degraded in planta, providing functional resistance to crown gall disease in walnut (Matthew et al., 2002). Likewise the strategy has been used for developing transgenics against citrus canker (Enrique et al., 2010), pox virus disease in plum (Scorza et al., 2001) and papaya ring spot virus (Krubphachaya et al., 2007). The major advantage of these new generation transgenics over current era transgenics is that the likely hood of insect and diseases developing resistance to the former is very rare. Quality traits in many crops have been improved by using RNAi against targeted genes. Using RNAi for MXMT (7methylxanthine methyl transferase (MXMT), yielded 70 per cent suppression of the caffeine level in leaves of transgenic coffee plants to cope with occasional health problems caused by caffeine uptake (Ogita $e t$ al., 2005). Silencing of ethylene biosynthesis in apple fruit via the suppression of ACS or ACO mRNA which resulted in fruits with significantly firm fruits and increased shelflife (Abahaya et al., 2004). Apples with significantly decreased level of major apple allergen, Mal $d 1$ using RNAi will allow most of the apple allergic patients to eat apple without allergic reactions (Gilissen et al., 2005). The functional genomics part has also been well explored in horticultural crops through RNAi, It is concluded that $S E P$ genes play a central role in the developmental regulation of ripening in both climacteric and non-climacteric fruits (Seymour et al., 2011). Silencing of a chalcone synthase (CHS) gene in strawberry fruits by a construct (ihpRNA) has elucidated that the gene plays a vital role in ripening of fruits (Hoffmann et al., 2006). Down regulation the ARRO-1 gene expression through RNAi has revealed the role of this gene in adventitious root formation in apple (Smolka et al., 2009). RNA interference (RNAi) is an advance technology which is highly effective and powerful tool of functional genomics for silencing the gene expression for fruit plant improvement. The RNAi technology, described in this article, describes one such powerful innovation. If judiciously used, this technology may go a long way to narrow the gap through production of disease, insect and virus resistant, nutritionally rich and toxic free fruits.

\section{Applications of RNAi in fruit crops}

In fruit crops the RNAi technique can be applied for functional genomics, transgenic for insect and disease resistance and down regulation of genes for quality improvement.

\section{Functional genomics}

Functional genomics is a field of molecular biology that is attempting to make use of vast wealth of data produced by genome sequencing projects to describe genome functions. RNAi transgenes are useful tools for the study of reverse genetics. A major challenge in the post-genomic era of plant 
biology is to determine the functions of all genes in the plant genome. Compared to other techniques, RNAi offers specificity and efficacy in silencing members of a gene or multiple gene family. In addition, the expression of dsRNAs with inducible promoters can control the extent and timings of gene silencing, such that essential genes are only silenced at chosen growth stages or plant organs. RNAi transgenes are also useful tools for the study of reverse genetics.

\section{Apple}

Adventitious root formation is a limiting factor for vegetative propagation in apple. The molecular mechanism underlying the process is still largely unknown and is to be extensively investigated. The Adventitious Rooting Related oxygenase (ARRO-1) has been isolated from apple and has been shown to be up regulated during adventitious root induction. However, the function of this gene is still unclear. Smolka et al., (2009) down regulate the ARRO-1 gene expression, using RNAi technique, to study the function of ARRO-1 in adventitious root formation in apple. The apple rootstock M26 was transformed with RNAi-ARRO-1 construct. The transgenic clones, confirmed by PCR and southern blot analysis showed significantly reduced adventitious root formation both with micro cuttings and stem discs, indicating the involvement of ARRO- 1 in adventitious root formation. The transgenic clones also appeared to be more sensitive to exogenous hormones compared to the untransformed control plants, suggesting that ARRO-1 is involved in regulation of hormone homeostasis.

\section{Strawberry}

RNA interference (RNAi) has been exploited as a reverse genetic tool for functional genomics in the non model species strawberry
(Fragaria $\times$ ananassa) since 2006. A SEPALLATA gene is involved in the development and ripening of strawberry (Fragaria ananassa) fruit, a non-climacteric tissue (Seymour et al., 2011). It has demonstrated that silencing a fruit- related SEP1/2- like (FaMADS9) gene in strawberry leads to the inhibition of normal development and ripening in the petal, achene, and receptacle tissues. Hoffmann et al., (2006) demonstrated the silencing of a ripening related chalcone synthase (CHS) gene in strawberry fruits ( $F$. ananasa cv Elsanta) by a construct (ihpRNA) containing the partial sense and corresponding antisense sequences of CHS separated by an intron obtained from a $F$. ananasa quinine oxireductase gene. An Agrobactrium strain carrying a T-DNA expressing the ihpRNA transgene was injecting with a syringe into receptacles of growing fruits still attached to the plant 14 days after pollination. As a consequence of the reduced levels of CHS mRNA and enzymatic CHS activity, the levels of anthocynanins were down regulated and precursors of the flavonid pathway were shunted to the phenylpropanoid pathway leading to a large increases in levels of (hydroxy) cinnamoyl glucose esters. The expression of CHS gene in fruit tissue is developmentally regulated and associated with fruit colouring has been shown in Rubus (Kumar and Ellis, 2003), apple (Honda et al., 2002), grapevine (Goto-Yamamoto et al., 2002). The effect of the reduction in CHS function was confirmed on the messenger RNA enzyme and metabolite level. This method may facilitate studies of gene function in strawberry fruits. Katja Hartl 2017analysed for the first time different but overlapping nucleotide sections (>200 nt) of two endogenous genes, $\mathrm{FaCHS}$ (chalcone synthase) and $\mathrm{FaOMT}(\mathrm{O}$-methyltransferase), as inducer sequences and a transitive vector system to compare their gene silencing efficiencies. In total, ten vectors were 
assembled each containing the nucleotide sequence of one fragment in sense and corresponding antisense orientation separated by an intron (inverted hairpin construct, ihp). All sequence fragments along the full lengths of both target genes resulted in a significant down-regulation of the respective gene expression and related metabolite levels. Quantitative PCR data and successful application of a transitive vector system coinciding with a phenotypic change suggested propagation of the silencing signal. The spreading of the signal in strawberry fruit in the $3^{\prime}$ direction was shown for the first time by the detection of secondary small interfering RNAs (siRNAs) outside of the primary targets by deep sequencing. Down-regulation of endogenes by the transitive method was less effective than silencing by ihp constructs probably because the numbers of primary siRNAs exceeded the quantity of secondary siRNAs by three orders of magnitude. Besides, we observed consistent hotspots of primary and secondary siRNA formation along the target sequence which fall within a distance of less than 200 nt. Thus, ihp vectors seem to be superior over the transitive vector system for functional genomics in strawberry fruit.

\section{Citrus}

Citrus canker is an important disease caused by Xanthomonas citri subsp. Citri (Xcc). RNAi as a functional genomics tool was employed to assess the function of candidate genes involved in the defence response of citrus lemon against the citrus canker pathogen. (Enrique et al., 2010). Double stranded RNA expression vectors, encoding hairpin RNAs for host genes, were delivered to lemon leaves by transient infiltration with transformed Agrobactrium. Silencing of citrus phytoene desaturase (PDS) and callose synthase (calS1) genes revealed that the plant cell- wall associated defence is the principal initial barrier against Xanthomonas infection in citrus plants. Results also suggested that hydrogen peroxide accumulation, which is suppressed by Xanthan from Xcc during pathogensis, contributes to inhibition of Xanthan- deficient Xcc mutant growth either in wild type or CalS1- silenced plants. With this work, it is demonstrated that highthrough reverse genetic analysis is possible in citrus.

Benedito et al., (2007) explored the CitEST database, with 242,7 90 Expressed Sequance Tags (ESTs), derived from 33 libraries of eight Citrus and one Poncirus species and represents a valuable platform for analyzing the genetic machinery involved in RNA silencing in citrus species. Identifying RNA silencing will allow a more accurate analysis of these mechanisms, helping to unravel evolutionary aspects. Moreover, mechanisms of gene silencing or silencing suppression may be used in citrus molecular breeding, since Citrus tristeza virus (CTV; Closterovirus), the most important virus of citrus orchards worldwide and holds three distinct silencing suppressors in its $\sim 20-\mathrm{kb}$ genome (Lu et al., 2004). Suppression of endogenous RNA silencing machinery in host cells by multiple mechanisms may represent the basis for virulence and infectively success. Thus, tackling CTV RNA silencing suppressors may also help to elucidate and identify possible mechanisms of resistance.

\section{Apple}

Abhaya et al., (2004) investigated the role of ethylene in regulating the fruit quality components like sugar, acid, texture and volatile components in transgenic apple fruit. Fruit obtained from plants silenced for either ACS (ACC synthase; ACC-1aminocylopropane-1-carboxylic acid) or ACO (ACC oxidase), key enzymes responsible for ethylene biosynthesis, expectedly showed 
reduced autocatalytic ethylene production. Ethylene suppressed fruits were significantly firmer than controls and displayed an increase shelf-life. No significant difference was observed in sugar or acid accumulation, suggesting that sugar and acid composition and accumulation is not directly under ethylene control. Interestingly, a significant and dramatic suppression of the synthesis of volatile esters was observed in fruit silenced for ethylene. However, no significant suppression was observed for the aldehyde and alcohol precursors of these esters. There results indicate that ethylene differentially regulates fruit quality components and the availability of these transgenic apple trees provides a unique resource to define the role of ethylene and other factors that regulate fruit development.

\section{Transgenics for insect and disease resistance}

The effects of gene silencing in plants were first used in efforts to develop resistance to diseases, particularly those caused by viruses, although the mechanism was not clear at the time. This 'pathogen-derived resistance' (PDR) was achieved by transforming plants with genes, or sequences, derived from the pathogen, with the aim of blocking a specific step in the life or infection cycle of the pathogen. Many of the strategies used for PDR were shown to be mediated by RNA, rather than protein, and led directly to the identification of PTGS - a phenomenon that is believed to be a form of anti-viral defence (Voinnet 2001, and Goldbach et al., 2003). An important finding, first recognized in plants, was that once triggered, the silencing spreads throughout the organism by virtue of a gene silencing signal (Voinnet et al., 1998), thus providing systemic rather than localized resistance. The effectiveness of RNAi technology for generating virus resistance in plants was first demonstrated in 1998.

\section{Banana}

The RNAi may be fruitfully applied in the production of banana varieties resistant to the Banana Bract Mosaic virus (BBrMV), which devastates the banana population in South east Asia and India (Rodoni et al., 1999). The BBrMV infects banana plants destroying the fruit producing bract region, rendering them useless to farmers. The virus is spread by small plant eating insects called aphids, as well as through infected plant materials. The problem is further compounded when further banana crops are raised in the infected field because the infection spreads from the previous diseased crop. However, by carefully designing an RNAi vector aimed at silencing the Coat Protein $(\mathrm{CP})$ region of the virus, scientists may be able to develop a banana variety that is resistant to BBrMV and yet safe to eat.

The CP region of the different strains of virus is highly conserved and as such silencing of this gene in other varieties of banana will not pose a problem. Another novel approach is to utilize an inducible promoter system in order that dsRNA is produced only upon infection and not constitutively.

\section{Walnut}

Matthew et al., (2002) developed a novel crown gall resistance strategy, in walnut. The tryptophan monooxygenec (iaaM) and isopentenyl transferase (ipt) genes are horizontally transferred from A. tumefaciens to the plant cell, mediating the de novo auxin and cytokinin production that initiates tumorigenesis. By expressing inducers of post- transcriptional gene silencing homologous to iaaM and ipt in plant cells, the corresponding oncogene mRNA transripits are degraded in planta, providing functional resistance to crown gall diseases. 


\section{Plum}

Virus diseases of fruit trees, including plum pox or sharka virus (PPV) of Prunus, cause extensive economic losses (Nemeth, 1994).control of the tree fruit virus diseses has been through the control of insect or nematodes, vectors, sanitation and quarantine, while the use of resistant germplasm for developing virus resistant cultivars is a preferred method of control.

The transformation of plants with viral genes, such as coat protein (CP), can provide novel virus resistant varieties or genes resources for breeding new resistant varieties.

Studies of viral transgene -mediated resistance may either be mediated through the production of transgene protein (Wilson, 1993) or RNA-mediated, RNA-mediated resistance may take the form of posttranscriptional gene silencing (PTGS) wherein mRNA is degraded in the cytoplasm soon after synthesis (Dehio and Schell, 1994; Tanzer et al., 1997).

PTGS has been associated with multiple transgene copies, particularly direct repeats of transgene coding region, particularly direct reapts of the transgene coding region, truncated or antisense insert (Kohli et al., 1999), methylation of the coding region (Jones et al., 1999). Scorza et al., (2001) reported the mechanism of PPV resistance shown by transgenic clone.

The nuclear transcription assays demonstrated that transcription rates of transgene PPV-CP was very high. PPV resistant clone contains a complex arrangement of transgene copies that includes the entire construct cassette and a berrant copies. Seedling carrying, this gene displayed CP transgene methylation, and exhibited a high level of resistance to PPV.

\section{Down regulation of gene for quality improvement}

\section{De caffeinated coffee plants}

Caffeine is a secondary metabolite against insects and pests attack in coffee, which has many adverse effects such as caeffine intoxication, anxiety and sleep disorders. The conventional way to obtain decaffeinated coffee is extraction of caffeine with solvents. The chemical elimination of caffeine is expensive and carries a risk of losing flavor. Three $\mathrm{N}$ - methyl transferase enzymes are involved in caffeine biosynthesis in coffee plants, CaXMT1, CaMXMT1, (Theobromine synthase), CaDXMTi (caffeine synthase), has been cloned and expressed (Uefuji et al., 2003). Ogita et al., (2005) has constructed transgenic coffee plants by silencing the gene expression of Theobromine synthase (CaMXMT1) using RNAi approach. They have designed hairpin constructs by with fragments from the 3' untranslated region of theobromine synthase mRNA and used these for Agrobactrium-mediated transformation of somatic embryos from Coffeea cenophora. The RNAi expression was under the control of CaMV35S promoter. The caffeine level was reduced upto $70 \%$ in leaves.

\section{Silencing the major apple allergen Mal d 1}

Food allergies are a major health concern in industrializes countries. Apples with significantly decreased levels of major apple allergen, Mal d 1, would allow most patients allergic to apple to eat apples without allergic reactions (Puhringer et al., 2000). Mal d 1 belongs to a group of Pathogenesis- Related Protein PR10. To inhibit the expression of Mal d 1 in plants by RNA interference, in vitro-grown apple plantlets were transformed with a construct coding for an intron-spliced hairpin containg a Mal d1- specific intron sequence and Mal d 1 expression was 
successfully reduced by RNAi (Gilissen et al., 2005).

\section{Strawberry}

The strawberry (Chandler) fruit undergoes a fast softening during ripening. Polygalacturonase (PG) activity is low during this process, but two ripening- related $\mathrm{PG}$ genes, FaPG1 and FaPG 2 have been cloned. Both genes are up-regulated during ripening and are negatively regulated by auxin. To further asses the role of FaPG1 on strawberry softening, (Quesada et al., 2009) constructed transgenic plants containing an antisense plants containing an asa quality parameters were measured in ripe fruits. Total PG activity was reduced in these lines when compared with control. Cell wall extracts from APG fruits showed a reduction in pectin solubilization and an increase in pectin's covalently bound to cell wall. The expression pattern of this gene indicated that it could be involved in the release of pectin oligosaccharins, which could be elicitors of ripening processes, rather than the bulk hydrolysis of pectin within the cell wall, because its expression was observed at the onset of ripening (Redondo- Nevado et al., 2001). So by inhibition of gene expression of FaPG1 improves significantly the firmness of ripe fruits and the postharvest behavior without affecting other fruit characteristics or fruit yield.

\section{Future}

Since its identification only twenty years ago, RNAi has become the technology of choice for plant scientists investigating gene function and manipulating plants to generate novel traits. Data on the stability of traits engineered through RNAi is not available but naturally occurring mutants that mimic the RNAi effect have been shown to be stable for 20 generations (Kusaba et al., 2003). The use of tissue-specific and inducible promoters should improve our ability to silence gene expression in only the target issues and when required, thus minimizing 'off-target' effects. An as yet unexplored possibility is the silencing of undesirable or pathogen genes in only the root-stock of grafted crops, such as fruit trees, and using the silencing signal to influence the scion. This would avoid some of the problems associated with gaining the public's acceptance of the use of the established transgenic technologies (i.e. the edible crop would be produced by nontransgenic tissues). The relatively small size of the transgene required for silencing, compared with conventional transgenic technologies (which frequently require the expression of whole genes), could enable multiple genes (pathogens) to be targeted in a single construct.

This would reduce the amount of manipulation and time required to achieve the desired trait, particularly when engineering alterations to multiple stages of a biochemical pathway or to multiple pathogens affecting a crop. For pathogens with high levels of variability, such as viruses, the ability to target shorter sequences should enable a broader-spectrum of resistance to be developed if suitable conserved sequences can be identified. Our understanding of RNAi has emerged from two areas of plant science; experiments creating transgenic plants grown in the USA used the action of small RNAs, even though this cellular mechanism was not completely understood. For example, Flavr Savr tomatoes showed delayed fruit ripening through suppression of the polygalacturonase enzyme (Sanders and Haitt 2005). GE papaya trees expressing papaya ring spot coat protein genes were planted for virus resistance (Chaing 2001). Today, researchers are engineering a variety of crops to produce small RNAs that will silence essential genes in insects, nematodes and pathogens, an 
approach called host-delivered RNAi (HDRNAi).

\section{Future prospects of RNAi in Fruit crops}

$>$ Gene function through reverse genetics

$>$ Inactivation of allergens and other undesirable characters

$>$ Room for improvement of orphan crops

$>$ Parthenocarpic fruits (Tomato a model crop)

$>$ Disease and insect resistance

$>$ Overruling Self-Incompatibility

\section{References}

Abhaya, M.D., Teo1 G, Defilippi1 B. G, Uratsu1 S. L and Andrew. 2004. Effect of down-regulation of ethylene biosynthesis on fruit flavor complex in apple fruit. Transgenic Research 13: 373-384.

Agrawal, N., Dasaradhi P. V. N, Mohmmed. A, Malhotra P, Bhatnagar R. K, and Mukherjee S K. 2003. RNA Interference: Biology, Mechanism, and Applications. Microbiology and Molecular Biology reviews 67: 657685.

Angaji, S., Hedayati S and Madani. 2010. Applications of RNA interference in plants. Plantomics Journal 3: 77-84.

Benedito, B. V., Faria L, Freitas- Astua. J and Figuereria A. 2007. Genetic machinery for RNA silencing and defence against virsus in citrus.Genetics and Molecular Biology 30: 991-996.

Dehio, C., and Schell J. 1994. Identification of plant genetic loci involved in posttr involved in posttranscriptional mechanism for meiotically reversible transgene silencing. Proc Natl Acad Sci USA 91: 5538-5542.

Enrique. R., Siciliano F, Favaro M. A, Gerhardt N, Roeschlin R, Rigano L,
Sendin, Castagnaro A, Vojnov A and Marano M. R. 2010. Novel demonstration of RNAi in citrus reveals importance of citrus callose synthase in defence against Xanthomonas citri subsp. citri. Plant Biotechnol J. pp. 1-14 no. doi: 10.1111/j 1467-7652.

Fire. A., Xu, S. O, Montgomery M. K, Kostas. A, Driver S. E and Mello C C. 1998. Potent and specific genetic interference by double-stranded RNA in Caenorhabditis elegans Nature 391: 806-811.

Gilissen L J., W. J Bolhaar, P, Matos C, Boone M. J, Krens F. A, Zuidmeer L, Leeuwen A, Akkerdaas J, HoffmannSommergruber K, Knust A. C, Bosch D, E Weg van de W, Ree van R. 2005. Silencing major apple allergen Mal d 1 using RNAi. J Allergy clinical Immunology 115: 364-6.

Goldbach R., Bucher, E and Prins M. 2003. Resistance mechanisms to plant viruses: an overview. Virus Research 92: 207-212.

GotoYamamoto., Wan J, Masaki K, Kobayashi S. 2002. Structure and transcripition of three chalcone synthase genes of grape vine (Vitis Vinifera). Plant Sci 162: 867- 872.

Hoffmann T., Kalinowski G and Schawab S. 2006. RNAi-induced silencing of gene expression in strawberry fruit (Fragaria ananassa) by agroinfiltration: a rapid assay for gene function analysis. The Plant Journal 48: 818-826.

Honda C., Kotoda N, Wada M, Kondo S, Kobayashi S, Soejima J, Zhang Z, Tsuda T and Moriguchi T. 2002. Anthocyanin biosynthetic genes are co-coordinately expressed during red coloration in apple skin. Plant Physiol. Biochem 40: 955-962.

Jones L., Hamilton A. J, Voinnet O, Thomas 
C. L, Maule A. J and Baulcombe D C. 1999. RNA-DNA interactions and DNA methylation in post transcriptional gene silencing.Plant Cell 11: 2291-2301.

Katja Härtl, Gregor Kalinowski, Thomas Hoffmann, Anja Preuss, and Wilfried Schwab. 2017. RNA i-mediated endogene silencing in strawberry fruit: detection of primary and secondary siRNAs by deep sequencing. Plant Biotechnological Journal 15(5): 658668.

Kohli A., Gahakawa D, Vain D.A and Christou P. 1999. Transgene expression in rice engineered through particle bombardment: molecular factors controlling stable expression and transgene silencing. Planta 208:88-97.

Krubphachaya P., Ju ek M and Kertbundit S. 2007. Induction of RNA-mediated Resistance to Papaya Ringspot Virus Type W. Journal of Biochemistry and Molecular Biology 40: 404-411.

Kusaba, M., Miyahara, K, Lida, S, Fukuoka H, Takario T, Sassa H, Nishimura, M. and Nishio, T. 2003. Low glutenin content 1: a dominant mutation that suppresses the glutenin multigene family via RNA silencing in rice. Pl. Cell.15: 1455-1467.

Kumar A., and Ellis B. E. 2003. A family of polyketide synthase gene expressed in ripening Rubus fruits. Phytochemistry 62: 513-526.

Ma. B L., Subedi K, Evenson L and Stewart G. 2005. Evaluation of detection methods for genetically modified traits in genotypes resistant to European corn borer and herbicides. J. Environ. Sci. Health 40, 633-644.

Mansoor S., Amin I, Hussain M, Zafar Y and Briddo R W. 2006. Engineering novel traits in plants through RNA interference. Trends in Plant Science
11: 559-565.

Matthew A., Escobar C. A, Leslie G H, McGranahan A and Dandekar M. 2002. Silencing crown gall disease in walnut (Juglans regia L.). Plant Science 163:591-97.

Nemeth M. 1994. History and importance of plum pox in stone-fruit production. EPPO Bul 24: 525-536.

Ogita S., Uefujib H, Morimoto M, Sano H. 2005. Metabolic engineering of caffeine production. Plant Biotechnology 22: 461-468.

Pühringer H., Moll D, HoffmannSommergruber K, Watillon B, Katinger H, Laimer da Câmara Machado, M. 2000. The promoter of an apple Ypr 10 gene, encoding the major allergen Mal d 1, is stress- and pathogen inducible. Plant Science, $152,35-50$.

Quesada M. A., Blanco-Portalea, Sara Pose and Pliego-Alfaro. 2009. Regulation of the FaPG1 Gene Reveals an Unexpected Central Role for Polygalacturonase in Strawberry Fruit Softening. Plant Physiology 150:10221032.

Redondo Nevado J., Moyano E, Medina Escober N, Caballero J L, and Munoz Blanco J. 2001. A fruit- specific and developmentally regulated endopolygalacturonase gene from strawberry (Fragaria ananassa cv Chandler). J Exp Bot 52:1941-1945.

Rodoni, B. C., Ahlawat, Y. S, Varma, A, Dale, J. L, and Harding R. M. 1997. Identification and characterization of banana bract mosaic virus in India. Plant Dis. 81:669-672.

Scorza R., Callahan A, Levy L, Damsteegt V, Webb K, Ravelonandro M. 2001. Post-transcriptional gene silencing in plum pox virus resistant transgenic European plum containing the plum pox potyvirus coat protein gene. 
Transgenic Research 10: 201-209. Seymour G B., Ryder C. D, Cevik V, Hammond J. P, Popovich A, King G J, Vrebalov J, Giovannoni J. J and Manning K. 2011. A SEPALLATA gene is involved in the development and ripening of strawberry (Fragaria $x$ ananassa Duch.) fruit, a nonclimacteric tissue. Journal of Experimental Botany 62:1179-1188.

Smolka A., Welander M, Olsson P, Holefors $A$ and Zhu. 2009. Involvement of ARRO-1 gene in adventitious root formation in apple Plant Science 177: 710-715.

Tanzer M. M., Thompson W. F, Law M. D, Wernsman E. A, UknesJones L, Hamilton A J, Voinnet O, Thomas C L, Maule A J and Baulcombe. 1997. Characterization of posttranscriptionally suppressed transgene expression that confers resistance to tobacco etch virus infection in tobacco. Plant Cell 9: 1411-1423.

Voinnet O. 2001. RNA silencing as plant immune system against virsuses. Trends in genetics 17:449-59.

Voinnet O and Vain P. 1998. Systematic spread of sequence specific transgene RNA degradation is initiated by localized introduction of ectopic promterless DNA Cell 95: 177-187.

Waterhouse P. M., Graham M. W and Wang M. B. 1998. Virus resistance and gene silencing in plants can be induced by simultaneous expression of sense and antisense RNA. Proc Natl Acad Sci U. S. A. 95: 13959-139646.

Wilson TMA. 1993. Strategies to protect crop plants against viruses: Pathogen derived resistance blossoms. Proc Nat Acad Sci USA 90: 3134-3141.

\section{How to cite this article:}

Amardeep Kour and Navjot Gupta. 2019. RNA Inference: A New Technology for Genetic Improvement of Major Fruit Species. Int.J.Curr.Microbiol.App.Sci. 8(03): 1209-1218.

doi: https://doi.org/10.20546/ijcmas.2019.803.143 